\title{
Comparando as Matrizes de Referência da PROVA BRASIL e do SARESP
}

\author{
Sílvia Aparecida Moreira Lima \\ Universidade de Taubaté (UNITAU)
}

\begin{abstract}
Resumo
Este artigo tem como objetivo fazer uma comparação entre as Matrizes de Referência de Língua Portuguesa do SARESP e da Prova Brasil, especificamente verificar as semelhanças e diferenças entre as Habilidades de Leitura cobradas em ambas as Matrizes. Essas duas Matrizes foram analisadas de modo qualitativo, com base em fundamentação teórica sobre o conceito de habilidades e competências de leitura, sobre a abordagem sociocognitiva de leitura e sobre o conceito bakhtiniano de gênero discursivo. O que justifica a necessidade de uma análise das Matrizes de Referência dessas duas avaliações para entender melhor o que elas exigem é o grande interesse dos professores de Língua Portuguesa a respeito dessas avaliações externas oficiais e a dúvida sobre as semelhanças e diferenças entre essas duas avaliações. Os resultados mostram que a Matriz do SARESP é mais completa e detalhada e contempla as habilidades cobradas pela Prova Brasil.
\end{abstract}

Palavras-chave: habilidades de leitura; Prova Brasil; SARESP; ensino de língua portuguesa.

\begin{abstract}
This article compares the portuguese language reference matrixes for SARESP and the Prova Brasil, and, with the aim of better understanding what they require, it specifically measures the similarities and differences between the reading skills required in both matrixes. They were analyzed qualitatively, based on the theoretical concepts of reading skills and competences, on the socio-cognitive reading approach, and on the Bakhtinian concept of genre. The justification for analyzing the reference matrixes of these two exams is the great interest of Portuguese language teachers and their doubts about the similarities and differences between these external official exams. The results of this study show that the SARESP matrix is more complete and detailed and covers the skills demanded by the Prova Brasil.

Key-words: reading skills; Prova Brasil; SARESP; portuguese language teaching.
\end{abstract}

\section{INTRODUÇÃO}

Existe um grande número de pesquisas sobre leitura, porém pouco chega ao conhecimento do professor de língua portuguesa em atividade a respeito das habilidades de leitura exigidas nas provas externas, como no Sistema de Avaliação de Rendimento Escolar do Estado de São Paulo - SARESP (SÃO PAULO, 2009) e na Prova Brasil (BRASIL, 2008). 
Atualmente os professores têm discutido muito a respeito do que é requerido nessas avaliações, e até mesmo as políticas públicas começaram a direcionar o olhar para seus resultados, tanto que o currículo da Rede Pública de Ensino do Estado de São Paulo foi reformulado para contemplar os conteúdos que desenvolvam as habilidades focadas no SARESP. O interesse pelo assunto vai além dos limites do estado de São Paulo porque todas as escolas do país realizam a Prova Brasil.

Nossa vivência profissional mostra que os professores de língua portuguesa ainda manifestam muitas dúvidas a respeito das duas Matrizes de Referência citadas e se perguntam até que ponto elas são semelhantes; se haveria possibilidade de tomar uma como referência para as atividades de leitura e assim satisfazer as exigências de ambas. Essa constatação justifica a necessidade de uma análise das Matrizes de Referência dessas duas avaliações citadas para um melhor entendimento do que elas exigem. Pesquisas dessa natureza podem oferecer subsídios para os professores de língua portuguesa elaborarem atividades de leitura que desenvolvam as habilidades exigidas dos alunos por essas provas, além de capacitá-los para atuarem socialmente com maior competência comunicativa.

O objetivo deste artigo é fazer uma comparação entre as Matrizes de Referência de Língua Portuguesa do SARESP para o $9^{\circ}$ ano e da Prova Brasil para o $9^{\circ}$ ano, especificamente verificar as semelhanças e diferenças entre as habilidades de leitura cobradas em ambas as Matrizes. Esses dois documentos foram analisados de modo qualitativo, com base em fundamentação teórica sobre o conceito de habilidades e competências de leitura, sobre a abordagem sociocognitiva de leitura e sobre o conceito bakhtiniano de gênero discursivo, pois esses conceitos perpassam as habilidades de leitura descritas na Matriz de Referência da Prova Brasil, como mostram Lopes-Rossi e Paula (2012). Temos por hipótese que o mesmo ocorre com as habilidades de leitura da Matriz de Referência do SARESP.

Este artigo se divide nas seções de fundamentação teórica, de comparação entre os descritores de habilidades de leitura das duas Matrizes, de análise das semelhanças e diferenças entre esses e de conclusão.

\section{FUNDAMENTAÇÃO TEÓRICA}

Esta seção apresenta um breve histórico das Matrizes de Referência do SARESP e da Prova Brasil, o conceito de habilidades e competências de leitura, aspectos principais da abordagem sociocognitiva de leitura e do conceito bakhtiniano de gênero discursivo. Inicia-se pela definição do termo Matriz de Referência: 
A realização de uma avaliação de sistema com amplitude nacional, para ser efetiva, exige a construção de uma matriz de referência que dê transparência e legitimidade ao processo de avaliação, informando aos interessados o que será avaliado. De acordo com os pressupostos teóricos que norteiam os instrumentos de avaliação, a Matriz de Referência é o referencial curricular do que será avaliado em cada disciplina e série, informando as competências e habilidades esperadas dos alunos. (BRASIL, 2011:17).

A primeira versão da Matriz de Referência da Prova Brasil foi criada em 1997, como explica o documento que a divulgou:

Em 1997, foram desenvolvidas as Matrizes de Referência com a descrição das competências e habilidades que os alunos deveriam dominar em cada série avaliada, permitindo uma maior precisão técnica tanto na construção dos itens do teste, como na análise dos resultados da avaliação. A construção dessas matrizes, como não poderia deixar de ser, não foi feita de maneira arbitrária. Foi realizada uma consulta nacional sobre os conteúdos praticados nas escolas de ensino fundamental e médio, incorporando a análise de professores, pesquisadores e especialistas sobre a produção científica em cada área que seria objeto de avaliação escolar e utilizando como referência as secretarias de educação estaduais e das capitais que apresentaram ao Inep os currículos que estavam sendo praticados em suas escolas. (BRASIL, 2011, p.9-10).

Embora a Matriz de Referência da Prova Brasil tenha sido desenvolvida em 1997, a primeira Prova Brasil só ocorreu em 2005. Por outro lado, o primeiro SARESP ocorreu em 1996 e só em 2007 começou a seguir uma Matriz de Referência, após uma reformulação, pois até então seguia a escala de proficiência do SAEB (Sistema de Avaliação da Educação Básica).

\begin{abstract}
A partir desse ano [2007], o Saresp passou a ser um sistema de avaliação em larga escala. Com a implantação da Proposta Curricular Unificada no Estado, concretizada nos programas "Ler e Escrever" para as séries iniciais e "São Paulo faz Escola" para as séries finais dos ensinos fundamental e médio, definiu-se uma Matriz de Avaliação, que estabelece as expectativas de aprendizagem propostas no currículo. As provas foram prétestadas e introduziram-se itens do Saeb nas provas, possibilitando a equalização dos resultados obtidos na mesma métrica de proficiência adotada nas avaliações nacionais. (CASTRO, 2009, p.14).
\end{abstract}

Ambas as Matrizes utilizam os mesmos conceitos de habilidades e competências de leitura. Competência é definida a partir de Perrenoud (1999, p.7) “competência é a capacidade de agir eficazmente em um determinado tipo de situação, apoiada em conhecimentos, mas sem limitar-se a eles”. Para Macedo (2003,p.42) “uma competência é mais do que um conhecimento”. O autor ressalta que ela pode ser explicada como um saber que se traduz na tomada de decisões, na capacidade de avaliar e julgar. Na Matriz de referência do SARESP encontramos a seguinte concepção de competência:

Competências cognitivas são modalidades estruturais da inteligência. Modalidades, pois expressam o que é necessário para compreender ou resolver um problema. Ou seja, valem por aquilo que integram, articulam ou configuram como resposta a uma pergunta. Ao mesmo tempo, são modalidades porque representam diferentes formas ou caminhos de se conhecer. Um mesmo problema pode ser resolvido de diversos modos. Há igualmente 
muitos caminhos para se validar ou justificar uma resposta ou argumento. (SÃO PAULO, 2009, p.14).

O conceito de habilidades também aparece nas duas Matrizes, portanto, uma breve conceituação será necessária. Vejamos como a Matriz do SARESP conceitua habilidades:

\begin{abstract}
Elas funcionam como indicadores ou descritores das aprendizagens que se espera os alunos terem realizado no período avaliado. Possibilitam, igualmente, pelo nível alcançado, ordenar posições e localizar cada escola, por intermédio do desempenho de seus alunos, no conjunto das escolas ou sistema educacional do Estado de São Paulo. Por essa razão, as habilidades devem ser caracterizadas de modo objetivo, mensurável e observável. Elas possibilitam saber o que é necessário que o aluno faça para dar conta e bem do que foi solicitado em cada questão ou tarefa. (SÃO PAULO, 2009, p.13).
\end{abstract}

O trabalho docente baseado na Matriz do SARESP, que será detalhada na próxima seção, deve, portanto, considerar que os conceitos de habilidade e competência se complementam mutuamente, mas não se confundem. Como explica Machado (2002), habilidade é uma competência de ordem específica (microcompetência), relacionada ao saber fazer uma determinada atividade; é mensurável, observável. Um feixe de habilidades somado à mobilização de recursos cognitivos (conhecimentos, valores, atitudes, habilidades, procedimentos) resulta numa competência. A competência é o caminho, é o “como fazer”, isto é, o saber articular os recursos, as estratégias ou procedimentos para resolver os problemas.

A Matriz do SARESP define 40 habilidades de leitura; a Matriz da Prova Brasil, 21. Pode-se observar que todas são de caráter bem específico, como "Localizar um argumento utilizado pelo autor para defender sua tese, em um texto argumentativo” (H13 da Matriz do SARESP) e “Inferir o sentido de uma palavra ou expressão” (D3 da Matriz da Prova Brasil). Ter competência leitora é muito mais do que dominar uma ou outra habilidade; é dominar uma grande quantidade de habilidades que permitam compreender, fazer inferências, construir diferentes sentidos de acordo com as condições de produção e circulação em que o texto está inserido.

Uma concepção de leitura compatível com esse conceito de competência leitora, como explica Lopes-Rossi (2011), e que se adota nesta pesquisa é a sociocognitiva. O conceito de leitura sofreu algumas modificações ao longo das últimas décadas. A primeira é, como explica Solé (1998, p.23), a mudança do conceito de leitura como decodificação para o de leitura como construção de sentidos. Acreditava-se que o texto era algo pronto, acabado e que bastava o leitor decodificá-lo que seu sentido já estava compreendido. O grande problema dessa concepção é o fato de se ignorarem completamente os processos cognitivos do leitor e seus conhecimentos prévios na produção de sentido para o texto. 
A concepção cognitiva de leitura, como explicam Solé (1998) e Kleiman (1989), passou também a ser conhecida como abordagem interativista a partir da década de 80 . O interesse das pesquisas nessa vertente teórica passou a recair nas operações cognitivas de processamento textual, mostrando que, para que ocorra a compreensão textual, o indivíduo ativa seus conhecimentos linguísticos, textuais e representados na memória enciclopédica. Como esses conhecimentos são individuais, cada leitor, portanto, poderá compreender o texto de forma distinta, de acordo com "a quantidade de conhecimento disponível a partir do texto e do contexto, bem como de suas crenças, opiniões e atitudes” (SOLÉ, 1998, p.22). Sendo assim, a significação dada ao texto pelo leitor pode ou não ser a intencionada por seu autor.

Nessa abordagem, são levados em consideração os conhecimentos prévios do leitor, pois o texto não explicita todos os sentidos possíveis; muitas informações ficam implícitas e podem ser inferidas pelo leitor - algumas inferências não são nem previstas pelo autor do texto, pois é impossível prever que conexões o leitor fará dos elementos do texto com seus conhecimentos prévios. A compreensão baseia-se fortemente na possibilidade de o leitor fazer inferências e as pesquisas mostraram que é possível ensinar aos leitores inexperientes estratégias metacognitivas (procedimentos) de leitura, que consistem em relacionar os conhecimentos prévios do leitor com as informações do texto de forma que ele possa construir sentidos para o texto por meio de inferências. As limitações dessa concepção cognitiva de leitura, como explica Lopes-Rossi (2011), são o fato de o conhecimento ser visto como uma atividade individual, de origem subjetivista, e o fato de a leitura não estar inserida num contexto sócio-histórico mais amplo.

A mudança de uma concepção cognitiva para uma sociocognitiva de leitura é observada, como explica Koch (2005), a partir do momento em que os estudos sobre cognição concluíram que a separação entre o cognitivo e o social é impossível. A partir disso, a concepção cognitiva de leitura passou por uma revisão. A autora destaca que a cognição é um fenômeno situado, sendo assim, o estudo exclusivo da mente para a compreensão das estratégias de construção do conhecimento pode ser um erro, pois a vida em sociedade é determinante em alguns comportamentos cognitivos. "A linguagem é tida como principal mediador da interação entre as referências do mundo biológico e as referências do mundo sociocultural” (KOCH, 2005, p.100). O conceito de conhecimento prévio do leitor passou por uma ampliação. No momento da compreensão textual, não se podem excluir os conhecimentos sociais (culturais) da situação de comunicação. Koch (2005, p.97) afirma que “todo processo de compreensão pressupõe, portanto, atividades do ouvinte-leitor, de modo 
que se caracteriza como um processo ativo e contínuo de construção - e não apenas de reconstrução”.

Para Marcuschi (2008, p.242), “o texto é um processo e pode ser visto como um evento comunicativo sempre emergente”. Isso significa que não está acabado, pois sua significação será dada pelo seu leitor, a partir de uma série de fatores contextuais, linguísticos e textuais. O leitor segue algumas regras de gramática e de boa formação linguística para não ter uma interpretação completamente diferente da pretendida pelo autor, porque o texto não é uma “caixinha de surpresa”, mas o leitor constrói sentidos que não estão explicitados no texto. Marcuschi (2008, p.242) discorre sobre esse aspecto:

\begin{abstract}
Os efeitos de sentido são produzidos pelos leitores ou ouvintes na relação com os textos, de modo que as compreensões daí decorrentes são fruto do trabalho conjunto entre produtores e receptores em situações reais do uso da língua. O sentido não está no leitor, nem no texto, nem no autor, mas se dá como um efeito das relações entre eles e das atividades desenvolvidas.
\end{abstract}

O autor ainda evidencia que, como os textos são históricos e se realizam em algum gênero discursivo, cada gênero requer uma forma diferente de ser entendido, o que já é um indicador do seu sentido.

Entende-se por gênero discursivo (ou gênero do discurso) uma "forma relativamente estável de enunciado oral ou escrito, produzido em situações de interação verbal, com função comunicativa determinada” (BAKHTIN, 1992, p.262). Esse autor postula que toda comunicação, em todos os campos da atividade humana, se dá através de gêneros do discurso, ou seja, de enunciados particulares que apresentam traços em comum, guardando certas semelhanças, que podem ser reconhecidas pelos usuários da língua como adequadas a determinadas situações de comunicação. Alguns exemplos de gêneros discursivos, dos mais comuns no dia a dia até os mais complexos: bilhete, receita culinária, contrato de compra e venda, conversa, palestra, conferência.

\title{
COMPARAÇÃO ENTRE AS MATRIZES DE REFERÊNCIA DO SARESP E DA PROVA BRASIL
}

A Matriz de Referência de Língua Portuguesa do SARESP para o $9^{\circ}$ ano estabelece 40 habilidades de leitura $(\mathrm{H})$, sendo 13 específicas sobre a compreensão do texto literário. A Matriz de Referência de Língua Portuguesa da Prova Brasil para o $9^{\circ}$ ano estabelece 21 habilidades de leitura, identificadas por descritores (D) da habilidade a que se referem. Por ser extensa, para a análise desta pesquisa, a Matriz do SARESP foi dividida em seis quadros, de 
acordo com os seis temas nos quais ela é dividida. A partir dessa divisão, será feita a comparação entre essa Matriz e a da Prova Brasil, que é menos extensa.

As habilidades de leitura da Matriz do SARESP são agrupadas em três grupos de competências cognitivas avaliadas no exame: Grupo I, Competências para observar: Refere-se aos esquemas presentativos ou representativos, propostos por Jean Piaget. Graças a eles, os alunos podem ler a prova, e perceber o que está sendo proposto nos textos, imagens, tabelas ou quadros, interpretar esse registro como informação e decidir sobre a alternativa que julgam mais correta. Grupo II, Competências para realizar: As habilidades relativas às competências desse grupo caracterizam-se pelas capacidades de o aluno realizar os procedimentos necessários às suas tomadas de decisão em relação às questões ou tarefas propostas na prova. Grupo III, Competências para compreender: Esses esquemas ou competências expressam-se de modo consciente e permitem compreensões próprias a esse nível de elaboração cognitiva (SÃO PAULO, 2009, p. 18).

O quadro 1, a seguir, explicita as habilidades de leitura referentes ao Tema 1 da Matriz de Referência de Língua Portuguesa do SARESP e os descritores de habilidades de leitura da Matriz da Prova Brasil correspondentes.

Quadro1: Referente ao tema 1: Reconstrução das condições de produção de textos

\begin{tabular}{|c|c|}
\hline SARESP & PROVA BRASIL \\
\hline $\begin{array}{l}\text { Tema } 1 \\
\text { Reconstrução das condições de produção e recepção de } \\
\text { textos }\end{array}$ & \\
\hline $\begin{array}{l}\text { H01 Identificar a finalidade de um texto, seu gênero e } \\
\text { assunto principal. (GI) }\end{array}$ & $\begin{array}{l}\text { D12 - Identificar a finalidade de textos de } \\
\text { diferentes gêneros }\end{array}$ \\
\hline $\begin{array}{l}\text { H02 Identificar os possíveis elementos } \\
\text { constitutivos da organização interna dos gêneros } \\
\text { escritos (não literários): propagandas institucionais, } \\
\text { regulamentos, procedimentos, fichas pessoais, } \\
\text { formulários, verbetes de dicionários ou enciclopédia, } \\
\text { notícias, cartazes informativos, folhetos de informação, } \\
\text { cartas-resposta, artigos de divulgação, artigos de } \\
\text { opinião, relatórios, entrevistas, resenhas, resumos, } \\
\text { circulares, atas, requerimentos, documentos públicos, } \\
\text { contratos públicos, diagramas, tabelas, legendas, } \\
\text { mapas, estatutos, gráficos, definições ou textos } \\
\text { informativos de interesse curricular. (GI) }\end{array}$ & $\begin{array}{l}\text { D10 Identificar o conflito gerador do } \\
\text { enredo e os elementos que constroem a } \\
\text { narrativa. }\end{array}$ \\
\hline $\begin{array}{l}\text { H03 Identificar os interlocutores prováveis de um } \\
\text { texto, considerando o uso de formas verbais } \\
\text { flexionadas no modo imperativo ou de determinado } \\
\text { pronome de tratamento. (GI) }\end{array}$ & $\begin{array}{l}\text { D 13- Identificar as marcas linguísticas } \\
\text { que evidenciam o locutor ou interlocutor } \\
\text { de um texto. }\end{array}$ \\
\hline
\end{tabular}

Fonte: Brasil (2011) e São Paulo (2009) 
Esse primeiro quadro mostra que o tema 1 da Matriz do SARESP: Reconstrução das condições de produção e recepção de textos apresenta três habilidades (H1, H2, H3), que são semelhantes aos descritores da Prova Brasil D12, D10, D13, respectivamente. No entanto, a comparação entre essas habilidades e esses descritores evidencia a maior completude das habilidades do SARESP, pois a H2 pode se aplicar aos vários gêneros discursivos existentes, enquanto o descritor D10 da Prova Brasil só se aplica a gêneros literários.

A H3 do SARESP é a habilidade de "identificar os interlocutores prováveis de um texto considerando o uso de formas verbais flexionadas no modo imperativo ou de determinado pronome de tratamento". Prevê a determinação do interlocutor por meio de alguns elementos linguísticos específicos (formas verbais ou pronomes), enquanto o descritor D13 da Prova Brasil, "Identificar as marcas linguísticas que evidenciam o locutor ou interlocutor de um texto”, é mais amplo; permite a consideração de qualquer elemento linguístico que permita identificar os interlocutores, como aspectos lexicais de variação sociolinguística (gírias, regionalismo, itens lexicais típicos de determinada classe social, faixa etária, grupo profissional etc.). Por isso a H3 do SARESP e o D13 da Prova Brasil não apresentam correspondência total.

O quadro 2, a seguir, explicita as habilidades de leitura referentes ao Tema 2 da Matriz de Referência de Língua Portuguesa do SARESP e os descritores de habilidades de leitura da Matriz da Prova Brasil correspondentes. 
Quadro 2: Referente ao tema 2: Reconstrução do sentido do texto

\begin{tabular}{|c|c|}
\hline SARESP & PROVA BRASIL \\
\hline \multicolumn{2}{|l|}{ Tema 2- Reconstrução do sentido do texto } \\
\hline $\begin{array}{l}\text { H04 Identificar o sentido restrito a determinada área de } \\
\text { conhecimento (técnica, tecnológica ou científica) de } \\
\text { vocábulo ou expressão utilizado em um segmento de } \\
\text { texto, selecionando aquele que pode substituí-lo por } \\
\text { sinonímia no contexto em que se insere. (GI). }\end{array}$ & $\begin{array}{l}\text { D3 Inferir o sentido de uma palavra ou } \\
\text { expressão. }\end{array}$ \\
\hline $\begin{array}{l}\text { H05 Localizar itens de informação explicita, relativos à } \\
\text { descrição de características de determinado objeto, } \\
\text { fenômeno, cenário, época ou pessoa. (GI) }\end{array}$ & $\begin{array}{l}\text { D1 Localizar informações explícitas em } \\
\text { um texto. }\end{array}$ \\
\hline $\begin{array}{l}\text { H06 Localizar e relacionar itens de informação explícita, } \\
\text { distribuídos ao longo de um texto. (GI) }\end{array}$ & $\begin{array}{l}\text { alizar informações explícitas em } \\
\text { o. }\end{array}$ \\
\hline $\begin{array}{l}\text { H07 Localizar informações explícitas no texto, com o } \\
\text { objetivo de solucionar um problema proposto. (GI) }\end{array}$ & $\begin{array}{l}\text { D1 Localizar informações explícitas em } \\
\text { um texto. }\end{array}$ \\
\hline $\begin{array}{l}\text { H08 Diferenciar ideias centrais secundárias; ou tópicos e } \\
\text { subtópicos de um texto.(GI) }\end{array}$ & $\begin{array}{l}\text { D9 Diferenciar as partes principais das } \\
\text { secundárias de um texto }\end{array}$ \\
\hline $\begin{array}{l}\text { H09 Organizar em sequência lógica itens de informação } \\
\text { explícita, distribuídos ao longo de um texto. (GII) }\end{array}$ & $\begin{array}{l}\text { D11 Estabelecer relação de causa e } \\
\text { consequência entre partes e elementos } \\
\text { de um texto. }\end{array}$ \\
\hline $\begin{array}{l}\text { H10 Estabelecer relações entre imagens (fotos, } \\
\text { ilustrações), gráficos, tabelas, info- gráficos e o corpo do } \\
\text { texto, comparando informações pressupostas ou } \\
\text { subentendida. }\end{array}$ & 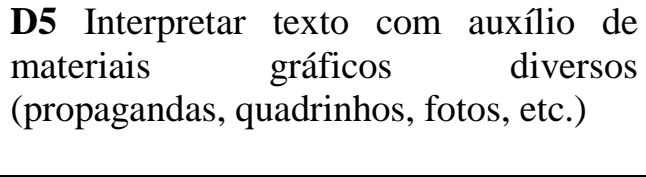 \\
\hline $\begin{array}{l}\text { H11 Inferir o tema ou o assunto principal, com base na } \\
\text { localização de informações explícitas no texto. (GIII) }\end{array}$ & D6 Identificar o tema de um texto. \\
\hline $\begin{array}{l}\text { H12 Inferir opiniões ou conceitos pressupostos ou } \\
\text { subentendidos }\end{array}$ & $\begin{array}{l}\text { D14 Distinguir um fato da opinião } \\
\text { relativa a esse fato em um texto. }\end{array}$ \\
\hline
\end{tabular}

Fonte: Brasil (2011) e São Paulo (2009)

O tema 2 do SARESP, Reconstrução dos sentidos do texto, traz as habilidades H4, H5, H6, H7, H8, H9, H10, H11 e H12, que apresentam algumas relações de semelhança com os descritores da PROVA BRASIL D3, D1, D1, D1, D9, D11, D5, D6 e D14, respectivamente. Destaca-se nessa comparação o fato de a H04, “Identificar o sentido restrito a determinada área de conhecimento (técnica, tecnológica ou científica) de vocábulo ou expressão utilizados em um segmento de texto, selecionando aquele que pode substituí-lo por sinonímia no contexto em que se insere”, ser uma habilidade de compreensão de vocabulário muito específica, enquanto o descritor da Prova Brasil que apresenta alguma semelhança com essa habilidade - D3 “Inferir o sentido de uma palavra ou expressão" - refere-se à compreensão de qualquer palavra ou expressão. Outro aspecto importante é o fato de o descritor 1 (D1) da Matriz da Prova Brasil se repetir no quadro comparativo e corresponder a 
três habilidades diferentes da Matriz do SARESP, o que mostra mais uma vez como os descritores da Prova Brasil apresentam características muito gerais.

Na comparação entre H09 “Organizar em sequência lógica itens de informação explícita distribuída ao longo de um texto" e D11 “Estabelecer relação de causa e consequência entre partes e elementos de um texto”, ambas relativas a raciocínio lógico, verifica-se uma diferença entre os verbos utilizados nas duas Matrizes e uma exigência maior da habilidade H09. Comparando as outras habilidades com os descritores desse Quadro 2, podemos verificar que a Matriz do SARESP é sempre mais específica na habilidade requerida, enquanto a Matriz da Prova Brasil expressa a habilidade de forma mais geral.

A H12 da Matriz do SARESP, "Inferir opiniões ou conceitos pressupostos ou subentendidos em um texto”, corresponde parcialmente a D14 da Prova Brasil, "Distinguir um fato da opinião relativa a esse fato”. Neste caso, observa-se que há diferença entre “inferir” e "distinguir”. Na H12, a operação cognitiva exigida (inferir) parece ser mais complexa, particularmente no que se refere a "conceitos pressupostos ou subentendidos em um texto”. A D14 exige apenas uma parte da habilidade exigida pela H12, portanto, a habilidade é mais complexa na Matriz do SARESP do que na Matriz da Prova Brasil.

O tema 3 do SARESP, Reconstrução da textualidade, apresenta sete habilidades que são comparadas com as habilidades correspondentes da Matriz de Referência da Prova Brasil no quadro 3 , a seguir. 
Quadro 3: Referente ao tema 3: Reconstrução da textualidade

\begin{tabular}{|l|l|}
\hline \multicolumn{1}{|c|}{ SARESP } & \multicolumn{1}{|c|}{ PROVA BRASIL } \\
\hline Tema 3 Reconstrução da textualidade & \multicolumn{1}{|c|}{} \\
\hline $\begin{array}{l}\text { H13 Localizar um argumento utilizado pelo autor } \\
\text { para defender sua tese, em um texto argumentativo. } \\
\text { (GI) }\end{array}$ & $\begin{array}{l}\text { D8-Estabelecer relação entre tese e os } \\
\text { argumentos oferecidos para sustentá-la. }\end{array}$ \\
\hline $\begin{array}{l}\text { H14 Identificar o sentido de operadores discursivos } \\
\text { ou de processos persuasivos utilizados em um texto } \\
\text { argumentativo. (GI) }\end{array}$ & $\begin{array}{l}\text { D15-Estabelecer relações lógico-discursivas } \\
\text { presentes no texto, marcadas por conjunções, } \\
\text { advérbios, etc. }\end{array}$ \\
\hline $\begin{array}{l}\text { H15 Estabelecer relações entre segmentos de um } \\
\text { texto, identificando o antecedente de um pronome } \\
\text { relativo ou o referente comum de uma cadeia de } \\
\text { substituições lexicais. (GII) }\end{array}$ & $\begin{array}{l}\text { D2-Estabelecer relações entre partes de um } \\
\text { texto, identificando repetições ou } \\
\text { substituições que contribuem para a } \\
\text { continuidade de um texto. }\end{array}$ \\
\hline $\begin{array}{l}\text { H16 Estabelecer relações de causa/ consequência } \\
\text { entre informações subentendidas ou pressupostas } \\
\text { distribuídas ao longo do texto. (GII) }\end{array}$ & $\begin{array}{l}\text { D11-Estabelecer relação de causa e e } \\
\text { consequência entre partes e elementos de um } \\
\text { texto. }\end{array}$ \\
\hline $\begin{array}{l}\text { H17 Distinguir um fato da opinião pressuposta ou } \\
\text { subentendida em relação a esse mesmo fato, em } \\
\text { segmentos descontínuos de um texto.(GII) }\end{array}$ & $\begin{array}{l}\text { D14-Distinguir um fato da opinião relativa a } \\
\text { esse fato. }\end{array}$ \\
\hline $\begin{array}{l}\text { H18 Inferir a tese de um texto argumentativo, com } \\
\text { base na argumentação construída pelo autor.(GIII) }\end{array}$ & D7-Identificar a tese de um texto. \\
\hline $\begin{array}{l}\text { H19 Justificar o efeito de sentido produzido, em um } \\
\text { texto, pelo uso intencional de notações e e } \\
\text { nomenclaturas específicas de determinada área do } \\
\text { conhecimento científico.(GIII) }\end{array}$ & $\begin{array}{l}\text { Não há nenhum descritor correspondente na } \\
\text { PB }\end{array}$ \\
\hline
\end{tabular}

Fonte: Brasil (2011) e São Paulo (2009)

O tema 3, Reconstrução da textualidade, apresenta sete habilidades, da H13 até a H19. Essas habilidades dizem respeito aos elementos coesivos do texto, por isso correspondem quase todas aos descritores da PB pertencentes ao tópico 4, que se refere à coerência e coesão no processamento do texto. A H19 não tem nenhum descritor correspondente na Matriz da Prova Brasil, pois essa Matriz não cobra habilidades que enfoquem aspectos específicos de gêneros da esfera científica.

O quadro a seguir traz o tema 4 da Matriz do SARESP, que engloba duas habilidades, a H20 e a H21. 
Quadro 4: Referente ao tema 4: Recuperação da intertextualidade e estabelecimento de relações entre textos

\begin{tabular}{|l|l|}
\hline \multicolumn{1}{|c|}{ SARESP } & \multicolumn{1}{|c|}{ PROVA BRASIL } \\
\hline $\begin{array}{l}\text { Tema 4: Recuperação da intertextualidade e } \\
\text { estabelecimento de relações entre textos }\end{array}$ & \\
\hline $\begin{array}{l}\text { H20 Justificar, om base nas características dos } \\
\text { gêneros diferenças ou semelhanças no tratamento } \\
\text { dado a uma mesma informação veiculada em } \\
\text { textos diferentes. (GIII) }\end{array}$ & $\begin{array}{l}\text { D20 Reconhecer diferentes formas de tratar } \\
\text { uma informação na comparação de textos que } \\
\text { tratam do mesmo tema, em função das } \\
\text { condições em que foi produzido e daquelas em } \\
\text { que será recebido. }\end{array}$ \\
\hline $\begin{array}{l}\text { H21 Justificar o uso de recurso a formas de } \\
\text { apropriação textual como paráfrases, citações, } \\
\text { discurso direto ou indireto livre em um } \\
\text { texto.(GIII) }>\text { Não há descritor correspondente na PB }\end{array}$ & \\
\hline
\end{tabular}

Fonte: Brasil (2011) e São Paulo (2009)

A H20 do SARESP é a habilidade de perceber como um mesmo tema é abordado de forma diferente em gêneros discursivos diferentes. O descritor D20 da Matriz da Prova Brasil também prevê a mesma habilidade e o trabalho com diferentes gêneros discursivos. H21 não encontra nenhum correspondente na Matriz da Prova Brasil, pois nessa Matriz não há nenhum descritor que enfoque "formas de apropriação textual”. Esse é mais um exemplo de uma habilidade bem específica cobrada pela Matriz do SARESP.

O quadro a seguir compara as habilidades do tema 5 da Matriz do SARESP, que faz uma reflexão sobre os usos da língua na fala e na escrita, com os descritores de habilidades correspondentes da Matriz da Prova Brasil. 


\section{Quadro 5: Referente ao tema 5: Reflexão sobre os usos da língua falada e escrita}

\begin{tabular}{|c|c|}
\hline SARESP & PROVA BRASIL \\
\hline $\begin{array}{l}\text { Tema } 5 \text { Reflexão sobre os usos da língua falada e } \\
\text { escrita }\end{array}$ & \\
\hline $\begin{array}{l}\text { H22 Identificar o uso adequado da concordância } \\
\text { nominal ou verbal, com base na correlação entre } \\
\text { definição/exemplo. (GI) }\end{array}$ & $\begin{array}{l}\text { Não há nenhum descritor correspondente na } \\
\text { PB }\end{array}$ \\
\hline $\begin{array}{l}\text { H23 Identificar o efeito de sentido produzido em } \\
\text { um texto pelo uso de determinadas categorias } \\
\text { gramaticais (gênero, número, casos, aspecto, modo, } \\
\text { voz etc.) (GI) }\end{array}$ & $\begin{array}{l}\text { D18 Reconhecer efeito de sentido decor- } \\
\text { rente da escolha de uma determinada palavra } \\
\text { ou expressão. }\end{array}$ \\
\hline $\begin{array}{l}\text { H24 Justificar a presença, em um texto, de marcas } \\
\text { de variação linguística no que diz respeito aos } \\
\text { fatores geográficos, históricos, sociológicos ou } \\
\text { técnicos, do ponto de vista da fonética, do léxico, } \\
\text { da morfologia ou da sintaxe. (GIII) }\end{array}$ & $\begin{array}{l}\text { D13 Identificar marcas linguísticas que evi- } \\
\text { denciam o locutor ou interlocutor de um } \\
\text { texto. }\end{array}$ \\
\hline $\begin{array}{l}\text { H25 Justificar a presença, em um texto, de marcas } \\
\text { de variação linguística que dizem respeito às } \\
\text { diferenças entre os padrões da linguagem oral e os } \\
\text { da escrita, do ponto de vista do léxico, da } \\
\text { morfologia ou da sintaxe.(GIII) }\end{array}$ & $\begin{array}{l}\text { D13 Identificar marcas linguísticas que } \\
\text { evidenciam o locutor ou interlocutor de um } \\
\text { texto. }\end{array}$ \\
\hline $\begin{array}{l}\text { H26 Aplicar conhecimentos relativos a unidades } \\
\text { linguísticas (períodos, sentenças, sintagmas) como } \\
\text { estratégia de solução de problemas de pontuação, } \\
\text { com base na correlação } \\
\text { definição/exemplo.(GIII) }\end{array}$ & $\begin{array}{l}\text { Não há nenhum descritor correspondente na } \\
\text { PB }\end{array}$ \\
\hline $\begin{array}{l}\text { H27 Aplicar conhecimentos relativos a regu- } \\
\text { laridades observadas em processos de derivação } \\
\text { como estratégia para solucionar problemas de } \\
\text { ortografia, com base na correlação entre } \\
\text { definição/exemplo.(GII) }\end{array}$ & $\begin{array}{l}\text { Não há nenhum descritor correspondente na } \\
\text { PB . }\end{array}$ \\
\hline
\end{tabular}

Fonte: Brasil (2011) e São Paulo (2009)

O tema 5 da Matriz do SARESP trata das relações existentes entre fala e escrita. Duas habilidades que correspondem a esse tema, a H24 e a H25, têm D13 da Prova Brasil como correspondente. A H23 é correspondente parcialmente ao D18, pois esse descritor só se refere a palavra ou expressão; já na Matriz do SARESP, a habilidade se refere a categorias gramaticais, ou seja, a Matriz do SARESP é mais detalhada, pois essa habilidade prevê que o efeito de sentido pode ser produzido pelo uso de diferentes categorias gramaticais, inclusive pelo uso de uma palavra no singular ou no plural. O descritor da PROVA BRASIL só contempla os diferentes sentidos causados por uma palavra ou expressão. Três habilidades cobradas pelo SARESP - H 22, H26 e H27, referentes a aspectos gramaticais e de ortografia não são contempladas pela Prova Brasil. 
O quadro a seguir compara as habilidades do tema 6 do SARESP, que trata da compreensão de textos literários, com descritores de habilidades da Prova Brasil.

Quadro 6: Referente ao tema 6: Compreensão de textos literários

\begin{tabular}{|c|c|}
\hline SARESP & PROVA BRASIL \\
\hline \multicolumn{2}{|l|}{ Tema 6: Compreensão de textos literários } \\
\hline $\begin{array}{l}\text { H28 Identificar o efeito de sentido produzido em um } \\
\text { texto literário pela exploração de recursos } \\
\text { ortográficos ou morfossintáticos. (GI) }\end{array}$ & $\begin{array}{l}\text { D19 Reconhecer o efeito de sentido } \\
\text { decorrente da exploração de recursos } \\
\text { ortográficos e/ ou morfossintáticos. }\end{array}$ \\
\hline $\begin{array}{l}\text { H29 Identificar o efeito de sentido produzido, em um } \\
\text { texto literário pelo uso intencional de pontuação } \\
\text { expressiva (interrogação, exclamação, reticências, } \\
\text { aspas, etc.). (GI) }\end{array}$ & $\begin{array}{l}\text { D17 Identificar o efeito de sentido } \\
\text { decorrente do uso de pontuação e de outras } \\
\text { notações. }\end{array}$ \\
\hline $\begin{array}{l}\text { H30 Identificar marcas do discurso indireto ou } \\
\text { indireto livre no enunciado de um texto literário } \\
\text { narrativo. (GI) }\end{array}$ & $\begin{array}{l}\text { Não há nenhum descritor correspondente na } \\
\text { PB }\end{array}$ \\
\hline $\begin{array}{l}\text { H31 Identificar recursos semânticos expressivos } \\
\text { (antítese, personificação, metáfora, metonímia) em } \\
\text { um segmento de um poema, a partir de uma dada } \\
\text { definição. }\end{array}$ & $\begin{array}{l}\text { Não há nenhum descritor correspondente na } \\
\text { PB }\end{array}$ \\
\hline $\begin{array}{l}\text { H32 Identificar uma interpretação adequada para um } \\
\text { determinado texto literário. (GI). }\end{array}$ & $\begin{array}{l}\text { Não há nenhum descritor correspondente na } \\
\text { PB }\end{array}$ \\
\hline $\begin{array}{l}\text { H33 Distinguir o discurso direto da personagem do } \\
\text { discurso do narrador, em uma narrativa literária. } \\
\text { (GII) }\end{array}$ & $\begin{array}{l}\text { Não há nenhum descritor correspondente na } \\
\text { PB }\end{array}$ \\
\hline $\begin{array}{l}\text { H34 Organizar os episódios principais de uma } \\
\text { narrativa literária em sequência lógica. (GII). }\end{array}$ & $\begin{array}{l}\text { Não há nenhum descritor correspondente na } \\
\text { PB }\end{array}$ \\
\hline $\begin{array}{l}\text { H35 Inferir o conflito gerador de uma narrativa } \\
\text { literária, analisando o enunciado na perspectiva do } \\
\text { papel assumido pelas personagens. (GIII). }\end{array}$ & $\begin{array}{l}\text { D10 Identificar o conflito gerador do enredo } \\
\text { e os elementos que constroem a narrativa. }\end{array}$ \\
\hline $\begin{array}{l}\text { H36 Inferir a perspectiva do narrador em uma } \\
\text { narrativa literária, justificando conceitualmente essa } \\
\text { perspectiva. (GIII) }\end{array}$ & $\begin{array}{l}\text { Não há nenhum descritor correspondente na } \\
\text { PB }\end{array}$ \\
\hline $\begin{array}{l}\text { H37 Inferir o papel desempenhado pelas personagens } \\
\text { em uma narrativa literária. (GIII) }\end{array}$ & $\begin{array}{l}\text { Não há nenhum descritor correspondente na } \\
\text { PB }\end{array}$ \\
\hline $\begin{array}{l}\text { H38 Justificar os efeitos pelo uso de palavras ou } \\
\text { expressões de sentido figurado. (GIII). }\end{array}$ & $\begin{array}{l}\text { D18 Reconhecer efeito de sentido } \\
\text { decorrente da escolha de uma determinada } \\
\text { palavra ou expressão. }\end{array}$ \\
\hline $\begin{array}{l}\text { H39 Justificar o uso de determinados recursos } \\
\text { gráficos, sonoros ou rítmicos em um poema. (GIII) }\end{array}$ & $\begin{array}{l}\text { D18 e D19 Reconhecer efeito de sentido } \\
\text { decorrente da escolha de uma palavra ou } \\
\text { expressão e/ou morfossintáticos. }\end{array}$ \\
\hline $\begin{array}{l}\text { H40 Justificar o efeito de humor ou ironia produzido } \\
\text { no texto literário pelo uso intencional de palavras ou } \\
\text { expressões. (GIII) }\end{array}$ & $\begin{array}{l}\text { D16 Identificar efeitos de ironia ou humor } \\
\text { em textos variados }\end{array}$ \\
\hline
\end{tabular}

Fonte: Brasil (2011) e São Paulo (2009)

O tema 6 da Matriz do SARESP trata de um grande número de habilidades: H28, H29, H30, H31, H32, H33, H34, H35, H36, H37, H38, H39 e H40. Como o tema é 
compreensão de textos literários, e na Matriz da Prova Brasil não há nenhum tópico que seja específico ao texto literário, dessas treze habilidades apenas seis encontram descritores correspondentes na PROVA BRASIL (D10, D17, D18 e o D19), como verificado no quadro acima. Esses são descritores bastante gerais, que se aplicam a inúmeros gêneros discursivos, literários e não literários. Uma análise mais detalhada dos descritores colocados lado a lado mostra que a correspondência entre eles não é perfeita. A H39 pede para justificar o uso de determinados recursos gráficos, sonoros ou rítmicos em um poema, por isso a correspondência com os descritores D18 e D19 é parcial, pois esses não são específicos para o texto literário (não se referem apenas a poemas). As outras sete habilidades do SARESP que não encontram correspondência na Prova Brasil referem-se exclusivamente ao texto literário.

No quadro 6, considerou-se que as habilidades H30, H33, H 36 e H37 do SARESP, referentes a marcas do discurso direto das personagens e à perspectiva do narrador, em uma narrativa literária, não encontram descritor correspondente na Matriz da Prova Brasil. Considerou-se que o D13 da Prova Brasil "Identificar as marcas linguísticas que evidenciam o locutor ou interlocutor de um texto" refere-se ao autor do texto (de um gênero discursivo) e a seu interlocutor, e não às personagens participantes do diálogo, no caso de um diálogo inserido em uma narrativa literária. “Texto”, nesse caso, não está sendo entendido como sinônimo de um diálogo inserido numa narrativa. Parece ser uma interpretação possível, dado que o descritor da Prova Brasil não é específico para textos literários.

Os resultados da comparação de habilidades de leitura da Matriz do SARESP e da Matriz da Prova Brasil evidenciam que a Matriz de referência do SARESP é mais recente e baseada na Matriz da Prova Brasil. No entanto, nota-se que as habilidades cobradas pelo SARESP são em número muito maior e mais específicas sobre o que estão avaliando. A Matriz de referência do SARESP detalha melhor as habilidades de leitura, explorando melhor o conceito bakhtiniano de gênero discursivo - especialmente nas H01, H02, H20 e nas 13 habilidades referentes à leitura de gêneros literários. A Matriz do SARESP também é mais específica quanto à percepção de marcas de variação lingüística, como se observa nas H24 e H25.

\section{CONCLUSÃO}

A análise das duas matrizes de referência permite concluir que as habilidades exigidas na Matriz de Referência do SARESP englobam todas as habilidades requeridas na Matriz de Referência da Prova Brasil. Essa primeira Matriz é mais completa e detalhada. Partindo desse resultado para a reflexão sobre o trabalho do professor de Língua Portuguesa interessado em 
desenvolver as habilidades exigidas por ambas as Matrizes de Referência, pode-se afirmar que os professores precisam ter subsídios teóricos sobre o conceito de habilidades de leitura; sobre dois dos principais conceitos envolvidos na leitura, de acordo com a abordagem sociocognitiva de leitura: decodificação e inferência; sobre o conceito bakhtiniano de gênero discursivo; sobre inúmeros aspectos constitutivos da textualidade e da variação lingüística de gêneros literários e não literários. Todos esses fundamentos teóricos perpassam as habilidades de leitura descritas na Matriz de Referência da Prova Brasil, como já mostraram Lopes-Rossi e Paula (2012), e também na Matriz de Referência do SARESP, como se pode notar na análise realizada nesta pesquisa.

Ainda considerando uma contribuição que os resultados desta pesquisa podem oferecer ao ensino de Língua Portuguesa, destaca-se a necessidade de que atividades de leitura para o desenvolvimento das habilidades previstas nas Matrizes analisadas sejam elaboradas a partir de gêneros discursivos diversos, uma vez que, para desenvolver desde as habilidades mais simples até as mais complexas, a diversidade de textos é fundamental. Conclui-se que ambas as Matrizes visam a capacitar os alunos a ler e interpretar em variadas situações comunicativas, bem como a compreender os fenômenos relacionados ao processo comunicativo que é característico de cada gênero. Esse processo mais amplo de compreensão exigido pelas Matrizes analisadas envolve uma competência linguística e comunicativa que será útil não só para práticas leitoras em sala de aula ou em provas, mas também para as mais diversas situações da vida.

\section{REFERÊNCIAS}

Bakhtin, M. (1992). Estética da criação verbal. São Paulo: Martins Fontes.

BRASIL. Ministério da Educação. (2008). PDE: Plano de Desenvolvimento da Educação: Prova Brasil: ensino fundamental: matrizes de referência, tópicos e descritores. Brasília: MEC, SEB; INEP.

Castro, M. H. G. (2009). Sistemas de avaliação da educação no Brasil: avanços e novos desafios. São Paulo em Perspectiva, São Paulo, v. 23, n. 1, p. 5-18. Disponível em: <http://www.seade.gov.br>; <www.scielo.br>. Acesso em: 07/06/2012.

Kleiman, Â. (1989). Leitura: ensino e pesquisa. Campinas: Pontes.

Koch, I. G. V. (2005). A construção dos sentidos no discurso: uma abordagem sociocognitiva. Investigações, v. 18, n.2. Recife, p. 9-38. 
Lopes-Rossi, M. A. G. (2011). Leitura de gêneros discursivos no ensino de Língua Portuguesa. Comunicação apresentada no IX Congresso Brasileiro de Linguística Aplicada CBLA. Rio de Janeiro: UFRJ.

Lopes-Rossi, M. A. G. \& Paula, O. de. (2012). As habilidades de leitura avaliadas pelo PISA e pela Prova Brasil: reflexões para subsidiar o trabalho do professor de Língua Portuguesa. Fórum Linguístico, Florianópolis, v. 9, n. 1, p. 34-46. Disponível em: $<$ http://www.periodicos.ufsc.br/index. php/forum >; Acesso em: 07/06/2012.

Macedo, L. (2003). Para o desenvolvimento de competências e habilidades na escola. In: Matos, C. (Org.). Ciência e arte: imaginário e descoberta. São Paulo: Estação Ciência, USP, p. 41-49.

Machado, N. J. (2002). Sobre a idéia de competência. In: Perrenoud, P. \& Thurler, M. G. (Org.). As competências para ensinar no século XXI: a formação dos professores e o desafio da avaliação. Porto Alegre: Artmed, p. 137-155.

Marcuschi, L. A. (2008). Produção textual, análise de gêneros e compreensão. São Paulo: Parábola.

Perrenoud, P. (2001). Dez novas competências para ensinar. Porto Alegre: Artmed.

PERRENOUD, Philippe. MAGNE, B. C. Construir: as competências desde a escola. Porto Alegre: Artmed, 1999.

SÃO PAULO. Secretaria Estadual da Educação. (2009). Matrizes de referência para a avaliação do rendimento escolar. São Paulo: SEESP.

Solé, Isabel. (1998). Estratégias de leitura. Trad. Cláudia Schilling. 6. ed. ArtMed: Porto Alegre.

\section{A AUTORA}

Sílvia Aparecida Moreira Lima é graduada em Letras pelas Faculdades Teresa Martin, mestranda em Linguística Aplicada na Universidade de Taubaté. Participa do Projeto Observatório da Educação/UNITAU 2011 - 2014 "Competências e habilidades de leitura: da reflexão teórica ao desenvolvimento e aplicação de propostas didático-pedagógicas”, $\mathrm{n}^{0}$ 23038010000201076, financiado por CAPES/INEP. É professora efetiva de Língua Portuguesa da Rede Estadual de Ensino do Estado de São Paulo.

E-mail: silmlima9@hotmail.com 